\title{
A welding technology using RobotStudio
}

\author{
Viorel Cohal* \\ Technical University of Iași, Department of TCM, Iași, Romania
}

\begin{abstract}
The paper presents the results obtained in designing a welding workstation by using offline programming in RobotStudio. The developed model was used to simulate welding elements of a welded assembly. Welding routes are obtained offline. By using ArcWelding module and VirtualArc there were obtained parameters of welding technology, which are automatically in WPS.
\end{abstract}

\section{Introduction}

This paper presents an embodiment of an assembly welding technology welding using a welding robot a robot. In this case, the model used is the IRB 140 robot programmed using software RobotStudio. To illustrate the simplicity of use of robot software and Virtual Studio Arc, programming and simulation of welding to achieve a welded assembly (Fig.1).

In this design phase welding technology was used a restraint system consists of several components that help the assembly welded assembly, welding operations in the order execution, using the robot. The system is constructed so as not to impede penetration of the robot arm with welding torch places for the welding process.

Finally both technological descriptions of the welding process and economic returns will be listed using Virtual Arc program, resulting in production price of welded subassembly according to production capacity and welding sequence of operations.

The final results on the computer and robot motion simulation and in the real environment during the welding process. This simulation is needed to determine the best angles for both the welding process and an economic use of the robot.

Programming the robot.

To program the robot is used IRB140 Robot Studio program, produced by ABB company, this is intended for off-line programming of robots from ABB range and simulation them within the workplace. RobotStudio is useful for programming, training in the use of robots and optimization program offering a number of advantages:

- eliminating the risk that exists when using real robots manual control.

- commissioning controller in a shorter time.

- opportunity to work with different types of effectors.

- ability to test a wider range of ABB robots.

- possibility to create and import your own objects, which can be saved in our database.

- interfacing with Visual Basic and Visual $\mathrm{C}++$

\footnotetext{
* Corresponding author: cohal@tcm.tuiasi.ro
} 


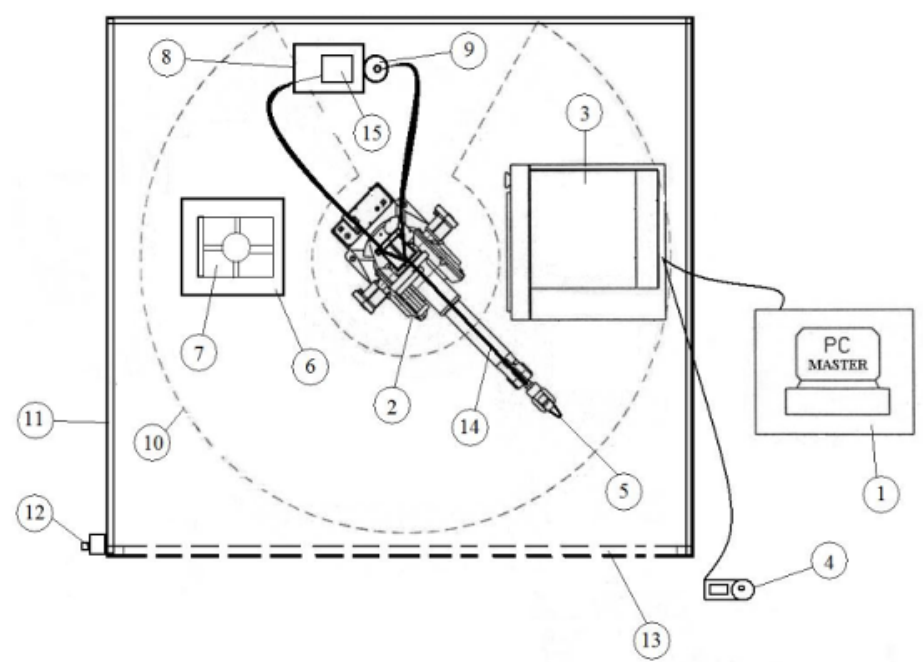

Fig. 1. Workstation 1. P.C. Master - computer connected to the controller; 2. Robot IRB 140; 3. Controller; 4. Console; 5. Gun; 6. Table; 7. Clamping system fixing piece; 8. Source; 9. Inert Gas Cylinder; 10. The robot operating area; 11. Fencing; 12. Control Panel-emergency; 13. Safety zone; 14. Cable.

Disadvantages simulation program:

- any simulator, it will not completely create real environment

- some positions must be redefined real robot,

- workstations component may have only one active robot with a controller

\section{Programming stages in Robotstudio}

For using RobotStudio in order to design and simulate an welding workstation, some specific requirements had to be fulfilled with the following stages:

1. Creating the workstation

$\checkmark$ Robot Choice

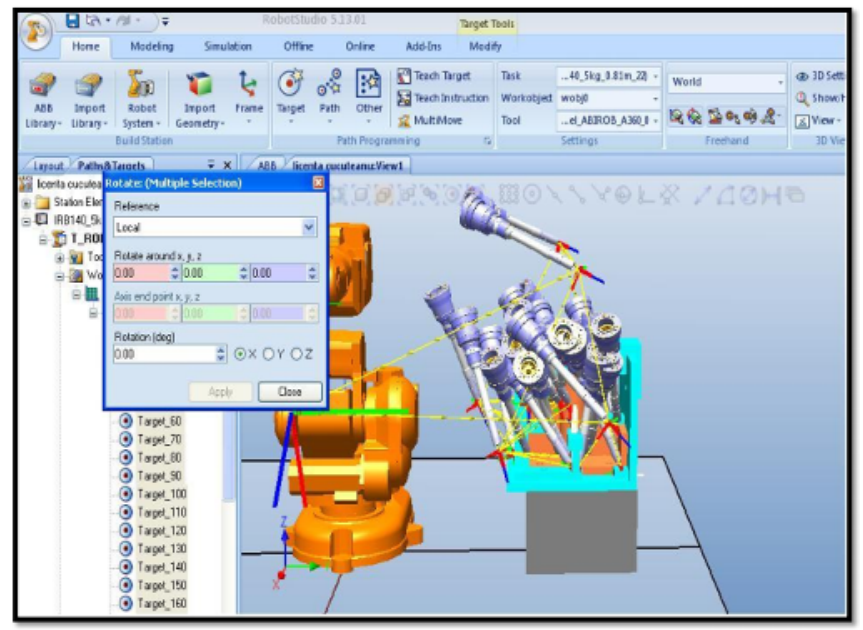

Fig. 2. Target. 
$\checkmark \quad$ milestones welding program has been projected (ex. Solid Edge, Solid Works, CATIA)

$\checkmark \quad$ Import-device mounting fixture and equipment.

2. Programming the robot
$\square \quad$ creation targets (Fig. 2)
$\square \quad$ create paths (Fig.3)
$\square \quad$ Check the collision, accessibility, self-configuration.
$\square$ offline simulation (Fig. 4)
$\square$ Saving console program

3. Creating work program online:

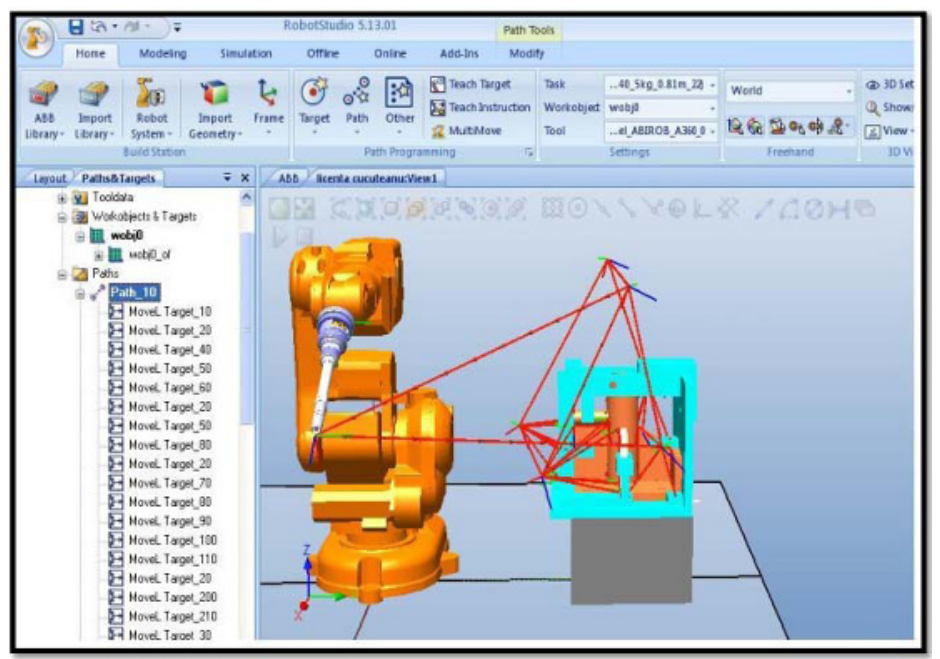

Fig.3. Path.

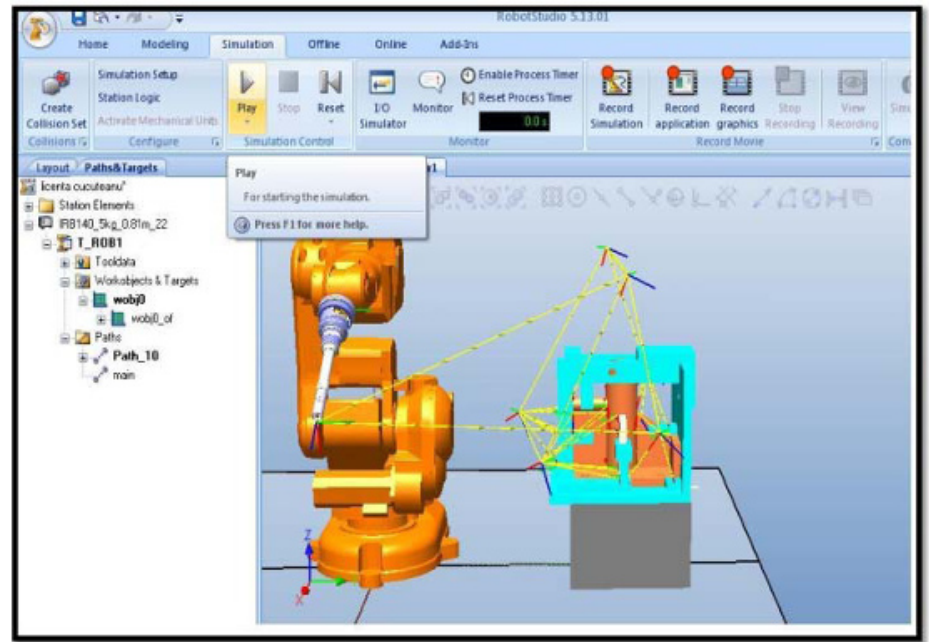

Fig.4. Offline simulation. 


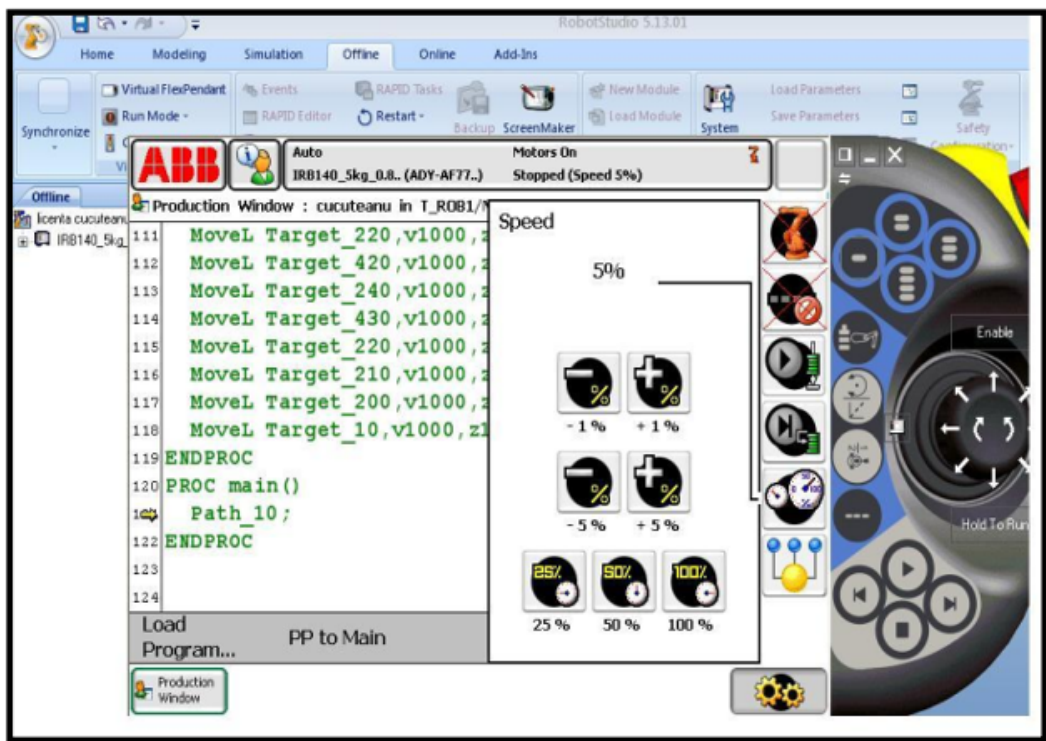

Fig.5. Speed control with flexpendant.

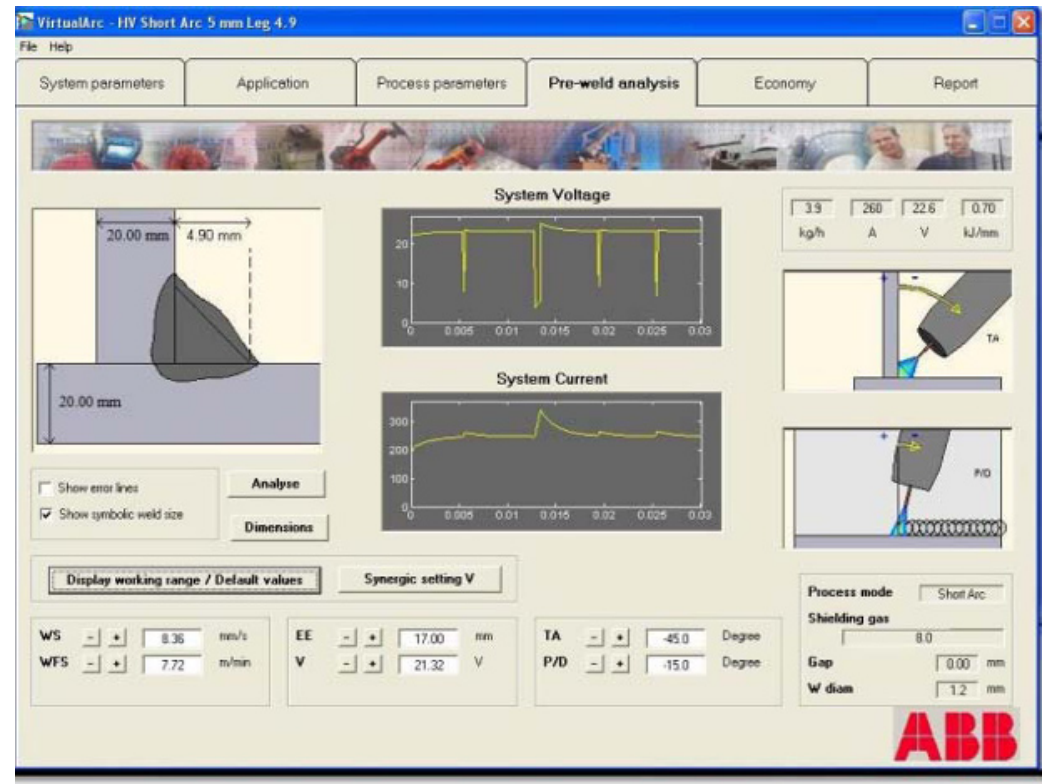

Fig.6. Analysis performed before welding using VirtualArc.

Creating the program is done using the console to manipulate the robot which is present in the virtual option program.

Creating software to be installed on the robot is entering the console menu and then select the "Program Editor". After loading will save the program so created that can be identified and stored in an easily accessible place to be copied to stick or to be charged directly from your PC to console. The next step is to load the program back into the console to be checked if it will work in real console. Robot speed is set depending on whether you are going to execute robot (Fig.5).

The last step is moving the robot program thus created by pressing the "play" of the console. 


\section{USING THE VIRTUAL ARC}

After the end stages of programming, engineering calculations on the robot and management can be done by software, a software module of Robot Studio, which is Virtual Arc.

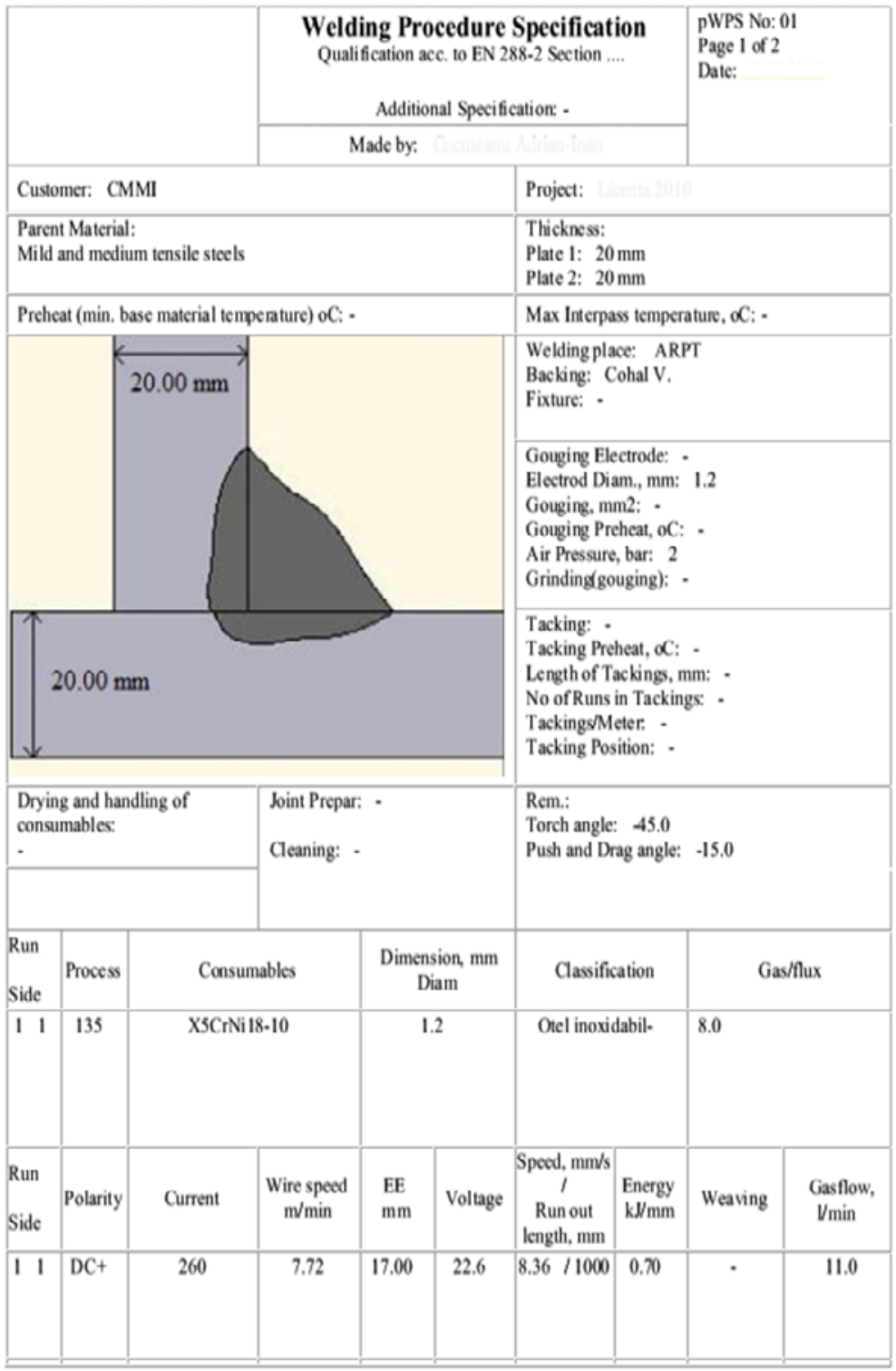

Fig.7. WPS using VirtualArc.

Opening Arc virtual program is in the "Add-Ins" module "ArcWelding" (fig.6).

Further complement the required values selected from the database or calculated:

$\square$ System parameters

$\square \quad$ Regimes welding process parameters

$\square$ Pre-weld analysis

$\square$ Elements on economic calculations 


\section{$\square$ Report}

Economic application will be completed as desired, depending on the number of pieces of operator costs, etc. At the end on the right will show the calculation results of the robot expenses and costs and the company that manufactures welded assembly.

Finally sheet resulting technological WPS (fig. 7). A Welding Procedure Specification (WPS) is the formal written document describing welding procedures, which provides direction to the welder or welding operators for making quality production welds as per the requirements. The purpose of the document is to guide welders to the accepted procedures so that repeatable and trusted welding techniques are used. A WPS is developed for each material and for each welding type used.

\section{CONCLUSIONS}

Using software RobotStudio is done offline work program the robot in a short time, being accomplished online testing reducing costs and development time of technological design. Arc program virtual appearance in Robot Studio enables a detailed view of the data sheet, which is displayed, and the formation of weld material inside out and eliminating errors.

\section{References}

1. V. Cohal, Workstation Design for Robot Welding using RobotStudio (in Romanian), (Ed. Politehnium, Iaşi, Romania, 2008)

2. V. Cohal, Programming robots for welding and simulation in RobotStudio, (in Romanian), (Ed. Politehnium, Iaşi, 2008)

3. VirtualArc ${ }^{\circledR}$ 1.1, ABB AB Robotics Products, S-721-68 Västerås, Sweden (2016)

4. Operating Manual ArcWelding PowerPac RobotStudio 6.02, Document ID: 3HAC028931-001, Revision: F, ABB AB Robotics Products, SE-721 68, Västerås, Sweden (2016)

5. Operating manual RobotStudio 6.02, Document ID: 3HAC032104-001, Revision: C, ABB AB Robotics Products, SE-721 68, Västerås, Sweden (2016) 